\title{
Stage specific upregulation of antioxidant defence system in leaves for regulating drought tolerance in chickpea
}

\author{
H. K. Oberoi* , A. K. Gupta, S. Kaur and I. Singh ${ }^{1}$ \\ Department of Biochemistry, Punjab Agricultural University, Ludhiana, INDIA \\ ${ }^{1}$ Department of Plant Breeding and Genetics, Punjab Agricultural University, Ludhiana, INDIA \\ *Corresponding author. E-mail: harpreetkaur_unio@yahoo.com
}

Received: May 19, 2014; Revised received: August 23, 2014 ; Accepted: September 15,2014

\begin{abstract}
Leaf is one of the early sensors for the drought stress and is important to study drought tolerance mechanism. Activities of antioxidative enzymes and status of malondialdehyde (MDA), hydrogen peroxide $\left(\mathrm{H}_{2} \mathrm{O}_{2}\right)$, proline and total phenols were studied in leaves of drought tolerant (PDG 3 and PDG 4) and susceptible (PBG 1, GPF 2, PBG 5, L 550 and BG1053) chickpea cultivars under irrigated and rainfed conditions at different development stages. In general, with the age of plant, the activities of superoxide dismutase (SOD) and catalase (CAT) increased but the activities of glutathione reductase (GR), ascorbate peroxidase (APX) and peroxidase (POX) decreased in leaves. With some exceptions, in general, higher status of APX and POX in leaves at vegetative stage I (30 days after sowing) and II (60 days after sowing); GR at vegetative stage II and pre-flowering stage and SOD and CAT at seed filling stages in tolerant cultivars under drought stress reflected stage specific upregulation of antioxidant defence system in them. The relatively lower activities of APX and POX in old leaves during seed filling stage make them more prone to enhanced oxidative injury than the young leaves. Lower content of hydrogen peroxide and malondialdehyde in leaves of tolerant cultivars during seed filling reflects the impact of antioxidant defence system operative at that time. The higher accumulation of proline and total phenol in leaves of tolerant cultivars might be playing important role in drought stress tolerance. These results indicated the importance of upregulation of different antioxidant enzymes at variable stages of leaf development.
\end{abstract}

Keywords: Antioxidative enzymes, Chickpea, Drought stress, Leaves

\section{INTRODUCTION}

Drought stress caused by soil and atmospheric water deficiency is one of the most significant environmental factors affecting plant growth and productivity worldwide (Salekjalali et al., 2012; Mirzaee et al., 2013). It disrupts major components of the photosynthesis process. Drought stress decreases intracellular $\mathrm{CO}_{2}$ concentration due to stomatal closure, and this causes suppression of the carboxylation reaction catalyzed by Rubisco, thus increasing photorespiration. A decrease in the photosynthetic fixation of $\mathrm{CO}_{2}$ reduces the consumption of ATP and NADPH during the Calvin cycle and this causes over-reduction in the photosynthetic electron transport chain due to insufficient electron acceptor $\mathrm{NADP}^{+}$. When ferredoxin is over reduced during photosynthetic electron transfer, electrons that have a high-energy state are transferred from the PS I to molecular oxygen forming the superoxide anion radical $\mathrm{O}_{2}{ }^{--}$via the Mehler reaction ( $\mathrm{Hsu}$ and $\mathrm{Kao}$, 2003; Labudda and Azam, 2014), which triggers chain reactions that generate more harmful oxygen radicals like $\mathrm{OH} \bullet$. As a result of drought stress, these reactive oxygen species (ROS) cause damage to cell structures, proteins, lipids, carbohydrates, and nucleic acids, leading to cell death. However, in spite of their damaging effects, under steady state conditions, ROS play a major physiological role in intracellular signalling and regulation, as secondary messengers (Gill and Tuteja, 2010).

To protect themselves against these toxic ROS, plants have evolved efficient systems which include ROS-scavenging antioxidative enzymes including superoxide dismutase (SOD), catalase (CAT), peroxidase (POX), ascorbate peroxidase (APX), glutathione reductase (GR), and non-enzymatic antioxidants including ascorbic acid, glutathione, carotenoids, and tocopherols (Ashraf, 2009; Singh et al., 2012; Verma et al., 2014). Among these, SOD converts $\mathrm{O}_{2}{ }^{--}$to $\mathrm{H}_{2} \mathrm{O}_{2}$ which is further scavenged by POX in extracellular space and cytosol; and mainly by CAT in peroxisomes. $\mathrm{H}_{2} \mathrm{O}_{2}$ is also decomposed by APX, one of the Asada-Halliwell enzymes, in different cell compartments. Hence, reacting directly or indirectly with ROS, enzymatic and non enzymatic antioxidants contribute in maintaining the integrity of cell structures and the proper functions of various metabolic pathways (Chaparzadeh et al., 2004). The degree to which the activities of antioxidant enzymes and the amount of antioxidants are elevated under drought stress shows a ISSN : 0974-9411 (Print), 2231-5209 (Online) All Rights Reserved @ Applied and Natural Science Foundation www.ansfoundation.org 
remarkable variation among plant species (Zhang and Kirkham, 1996; Turkan et al., 2005) and even between two cultivars of the same species (Bartoli et al., 1999; Perez-Lopez et al., 2009). In recent years, many researchers have established that the induction of the cellular antioxidant machinery is important for tolerance to drought stress (Miller et al., 2010; Chugh et al., 2011; Singh et al., 2012).

Drought stress is a major concern affecting the agriculture production. Generally pulses are very susceptible to drought stress. Chickpea is the second largest cultivated grain legume in the world, grown in about 11.5 million hectares (Varshney et al., 2013) and first in the Mediterranean basin and South Asia that frequently experiences water stress during pod set and seed filling stage (terminal drought) in India and the Mediterranean basin, leading to a substantial yield loss (Turner et al., 2001). As there is reduction in the translocation of carbohydrates during drought stress, this leads to a change in source-sink relationship (Patel and Hemantaranjan, 2012). Over past several years, there has been a great interest in research investigating the antioxidant defence system in plant leaves, as leaf is the principle plant part which acts as one of the early sensor for the drought stress. It has been demonstrated that the antioxidative response is correlated with the tolerance of individual crop cultivars to drought (Kolarovic et al., 2009).

Most of the studies reported in the literature either focussed on seedlings or if in the field then on one particular stage (Patel and Hemantaranjan, 2012; Kaur et al., 2012; Devi et al., 2012; Battana and Ghanta, 2014). The present study was conducted to study the antioxidant defence response at different developmental stages i.e. vegetative stages, pre-flowering and seed filling stages of the crop to see if there is any differential development specific response of tolerant genotypes to drought. Furthermore, the level of some compounds (proline, phenolics, malondialdehyde and hydrogen peroxide) were considered in an effort to identify the mechanism (s) by which drought stress decreases plant growth.

\section{MATERIALS AND METHODS}

Plant material and experimental conditions: Tolerant desi (PDG 3 and PDG 4), susceptible desi (PBG 1, GPF 2 and PBG 5) and susceptible kabuli (L 550 and BG 1053) chickpea cultivars were raised in the field of Punjab Agricultural University (30 54 'N, $75^{\circ} 48^{\prime} \mathrm{E}$, elevation $247 \mathrm{~m}$ above sea level), Ludhiana, following recommended agronomic practices. The crop was sown in the last week of November, 20082009 in sandy loam fields with $\mathrm{pH}$ of about 7.8 to 8.0 in randomized block design with three replicates of each cultivar under rainfed and irrigated conditions. Each plot had five rows of each cultivar with row length of $4 \mathrm{~m}$ and row spacing of $30 \mathrm{~cm}$ and there were 20-30 plants in each row. In irrigated area, 3 irrigations were given after sowing i.e. on $21^{\text {th }}$ December, $28^{\text {th }}$ January and $5^{\text {th }}$ March and plants grown in irrigated area received $369.4 \mathrm{~mm}$ water. However, under rainfed conditions all the three irrigations were withheld from sowing to maturity and the plants received water only available through rainfall. The average rainfall during the crop season was $44.4 \mathrm{~mm}$ and rainfed crops in total received $144.4 \mathrm{~mm}$ water (Table 1). It is cleared from the rainfall data that during the crop season rainfall was scanty resulted in development of drought stress. The plants were uprooted by deep burrowing from the field at the interval of 30 days and were collected at 30, 60, 90 and 120 days after sowing (DAS) and brought buried under ice to the laboratory. These stages have been named as vegetative stage I (VS I), vegetative stage II (VS II), pre-flowering stage (PF) and seed filling stage (SF).

Extraction and assay of antioxidative enzymes: All extractions were conducted in three replicates at $4^{\circ} \mathrm{C}$. SOD, POX and GR were extracted by homogenizing the leaf samples ( $1^{\text {st }}$ to $3^{\text {rd }}$ apical leaf) in $0.1 \mathrm{M}$ phosphate buffer (pH7.5) containing $1 \%$ polyvinylpyrrolidone (PVP), $1 \mathrm{mM}$ EDTA and $10 \mathrm{mM} \beta$-mercaptoethanol. CAT and APX were extracted with $0.05 \mathrm{M}$ phosphate buffer (pH 7.5) containing 1\% PVP (Kaur et al., 2009). Both the homogenates were centrifuged at $10,000 \mathrm{~g}$ for $20 \mathrm{~min}$ and the supernatant was used for assaying above mentioned enzymes. All enzymes were assayed at $30^{\circ} \mathrm{C}$. Components of enzyme assay system, except the enzyme were preincubated at $30^{\circ} \mathrm{C}$ for $20 \mathrm{~min}$ before starting the reaction.

Activity of APX was assayed by taking $1 \mathrm{ml}$ of $50 \mathrm{mM}$ sodium phosphate buffer ( $\mathrm{pH} 7.0$ ), $0.8 \mathrm{ml}$ of $0.5 \mathrm{mM}$ ascorbic acid, $0.2 \mathrm{ml}$ of enzyme extract and $1 \mathrm{ml}$ of $\mathrm{H}_{2} \mathrm{O}_{2}$ solution in total volume of $3 \mathrm{ml}$ (Nakano and Asada, 1987). Absorbance was recorded at $290 \mathrm{~nm}$ at an interval of $30 \mathrm{sec}$ upto $3 \mathrm{~min}$. Extinction coefficient of monodehydroascorbic acid was $2.8 \mathrm{mM}^{-1} \mathrm{~cm}^{-1}$. APX activity was expressed as $\mu$ moles of mono dehydroascorbic acid formed $\mathrm{min}^{-1} \mathrm{mg}^{-1}$ protein $\mathrm{FW}$.

Activity of CAT was determined by taking $1.8 \mathrm{ml}$ of $50 \mathrm{mM}$ sodium phosphate buffer ( $\mathrm{pH} 7.5$ ) to which 0.2 $\mathrm{ml}$ of enzyme extract was added. The reaction was initiated by adding $1 \mathrm{ml} \mathrm{H} \mathrm{O}_{2}$ and utilization of $\mathrm{H}_{2} \mathrm{O}_{2}$ was recorded at an interval of $30 \mathrm{sec}$ for $3 \mathrm{~min}$ by measuring the decrease in absorbance at $240 \mathrm{~nm}$ (Chance and Machly, 1955). Extinction coefficient for $\mathrm{H}_{2} \mathrm{O}_{2}$ was $0.0394 \mathrm{mM}^{-1} \mathrm{~cm}^{-1}$. CAT activity was expressed as $\mu$ moles of $\mathrm{H}_{2} \mathrm{O}_{2}$ decomposed $\min ^{-1} \mathrm{mg}^{-1}$ protein FW.

Assay system of SOD contained $1.4 \mathrm{ml}$ of $100 \mathrm{mM}$ Tris $\mathrm{HCl}$ buffer ( $\mathrm{pH} \mathrm{8.2),} 0.5 \mathrm{ml}$ of $6 \mathrm{mM}$ EDTA, $1 \mathrm{ml}$ of $6 \mathrm{mM}$ pyrogallol solution and $0.1 \mathrm{ml}$ of enzyme extract (Marklund and Marklund, 1974). Change in absorbance was recorded at $420 \mathrm{~nm}$ after an interval of $30 \mathrm{sec}$ upto $3 \mathrm{~min}$. A unit of enzyme activity was expressed as the amount of enzyme causing 50\% inhibition of auto-oxidation of pyrogallol observed in 
blank.

Assay of GR contained $0.2 \mathrm{ml}$ of $200 \mathrm{mM}$ potassium phosphate buffer ( $\mathrm{pH} 7.5), 0.1 \mathrm{ml} \mathrm{MgCl}_{2}(1.5 \mathrm{mM}$ ), $0.1 \mathrm{ml}$ EDTA $(0.2 \mathrm{mM}), 0.2 \mathrm{ml} \mathrm{NADPH}(0.025 \mathrm{mM})$, $0.2 \mathrm{ml}$ enzyme extract, followed by $0.2 \mathrm{ml}$ of oxidized glutathione $(0.25 \mathrm{mM})$ in a quartz cuvette (Esterbauer and Grill, 1978). Decrease in absorbance at $340 \mathrm{~nm}$ after an interval of $30 \mathrm{sec}$ upto $3 \mathrm{~min}$ was recorded. The molar extinction coefficient for NADPH was 6.22 $\mathrm{mM}^{-1} \mathrm{~cm}^{-1}$. GR activity was expressed as $\eta$ moles of $\mathrm{NADP}^{+}$formed $\mathrm{min}^{-1} \mathrm{mg}^{-1}$ protein $\mathrm{FW}$.

Assay system of POX contained $3 \mathrm{ml}$ of $0.05 \mathrm{M}$ guaiacol in $100 \mathrm{mM}$ phosphate buffer $(\mathrm{pH} 6.5), 0.1 \mathrm{ml}$ of enzyme extract and $0.1 \mathrm{ml}$ of $0.8 \mathrm{M} \mathrm{H}_{2} \mathrm{O}_{2}$ (Shannon et al., 1966). The reaction mixture without $\mathrm{H}_{2} \mathrm{O}_{2}$ was taken as a blank. The reaction was initiated by adding $\mathrm{H}_{2} \mathrm{O}_{2}$ and rate of change in absorbance was recorded at $470 \mathrm{~nm}$ for $3 \mathrm{~min}$ at an interval of $30 \mathrm{sec}$. POX activity was expressed as change in absorbance $\min ^{-1} \mathrm{mg}^{-1}$ protein FW. Protein content of all enzyme extracts was determined by the method of Lowry et al. (1951).

Extraction and estimation of $\mathrm{H}_{2} \mathrm{O}_{2}$ and Malondialdehyde: $\mathrm{H}_{2} \mathrm{O}_{2}$ was extracted from $500 \mathrm{mg}$ of leaf tissue with $3 \mathrm{ml}$ of ice cold $10 \mathrm{mM}$ potassium phosphate buffer ( $\mathrm{pH}$ 7.5) and was estimated according to the procedure of Noreen and Ashraf (2009). Malondialdehyde was extracted from $1.0 \mathrm{~g}$ of leaf tissue with $4 \mathrm{ml}$ of $5 \%$ (w/v) trichloroacetic acid and the homogenate was centrifuged at $12,000 \mathrm{~g}$ for $15 \mathrm{~min}$ at room temperature. The supernatant was used for estimation of malondialdehyde (MDA) (Heath and Packer, 1968).

Extraction and estimation of proline and total phenols: Approximately, $100 \mathrm{mg}$ of sample was homogenized with $4 \mathrm{ml}$ of $3 \%$ aqueous sulfosalicyclic acid and the homogenate was filtered through Whatman filter paper and filterate was used for proline estimation by the procedure of Bates et al. (1973). Total phenols was refluxed with $80 \%$ methanol and then volume was made with $80 \%$ methanol to $10 \mathrm{ml}$ and total phenols were then estimated (Swain and Hills, 1959).

\section{RESULTS}

Superoxide dismutase (SOD): It was observed that SOD increased in PBG 1 under rainfed conditions. In other susceptible desi cultivar GPF 2 increase in SOD was observed only at seed filling stage and in PBG 5 reduction in SOD was recorded throughout plant development under rainfed conditions (Fig. 1). On the other hand, under rainfed conditions kabuli cultivars showed higher activity at vegetative stage II and pre-flowering stage and reduction at seed filling stage. However, drought did not result in increase in SOD activity in leaves of tolerant (PDG 3 and PDG 4) and GPF 2 cultivars till pre-flowering stage, while a significant increase in SOD activity was observed at seed filling stage when compared to irrigated conditions.
In PBG 1 and kabuli (L 550 and BG 1053) cultivars, activity increased at vegetative stage II and pre-flowering stage and thereafter kabuli cultivars showed significant decline in activity at seed filling stage (Fig. 1).

PBG 5, GPF 2 and BG 1053 susceptible cultivars were severely affected due to drought stress and decline in mean SOD activity as well as specific activity was observed. When compared with irrigated conditions, 1.5 fold increases in average SOD specific activity was found in PBG 1, and comparable activity was observed in L 550 under rainfed environment. In case of drought stress, tolerant genotypes showed much higher increase in SOD specific activity over the activity seen in leaves of irrigated control plants at all growth stages and throughout the plant development period.

Catalase (CAT): An increase in catalase activity and specific activity was observed in the leaf tissue with the age of plant. In PBG 1 and tolerant (PDG 3 and PDG 4) cultivars, significant increase in CAT activity under rainfed conditions at all the stages as compared to irrigated conditions was observed (Fig. 2). However, in PBG 5 significant increase in CAT activity was observed only upto vegetative stage II and then comparable or lower activity was recorded. Tolerant cultivars PDG 3 and PDG 4, as compared to their activity at pre-flowering stage, had significantly higher activity of about 3 fold and 1.7 fold, respectively, under rainfed condition at seed filling stage. On the other hand, kabuli cultivars (L 550 and BG 1053) showed significant 2.2 fold increase in CAT activity at seed filling stage under irrigated conditions (Fig. 2).

The average catalase activity and specific activity under drought stress were significantly higher in drought tolerant PDG 3 and PDG 4 desi chickpea cultivars as compared to susceptible cultivars (Desi-PBG 1, GPF 2 and PBG 5 and Kabuli- L 550 and $\mathrm{BG}$ 1053) in comparison to activities observed under irrigated conditions. An average increase in CAT specific activity was found to be $103.7 \%$ and 76.2\% in tolerant PDG 3 and PDG 4 desi chickpea cultivars under rainfed conditions. Out of five susceptible cultivars, in PBG 1 and L 550 have increased average

Table 1. Rainfall data and irrigation schedule during chickpea development.

\begin{tabular}{lllc}
\hline Treatment & 2008-2009 & $\begin{array}{c}\text { Rainfall } \\
(\mathbf{m m})\end{array}$ & $\begin{array}{c}\text { Total water } \\
(\mathbf{m m})\end{array}$ \\
\hline \multirow{4}{*}{ Rainfall } & 2 Jan 2009 & 8.6 & \\
& 3 Jan 2009 & 9.8 & \\
& 7 Feb 2009 & 2.0 & 44.4 \\
& 8 Feb 2009 & 23.0 & \\
& 4 Mar 2009 & 1.0 & \\
Irrigation & 21 Dec 2008 & 75 & \\
& 28 Jan 2009 & 75 & 225 \\
& 5 Mar 2009 & 75 & \\
\hline
\end{tabular}

* Pre-irrigation of $100 \mathrm{~mm}$ was given to all the cultivars irrespective of the treatment. 

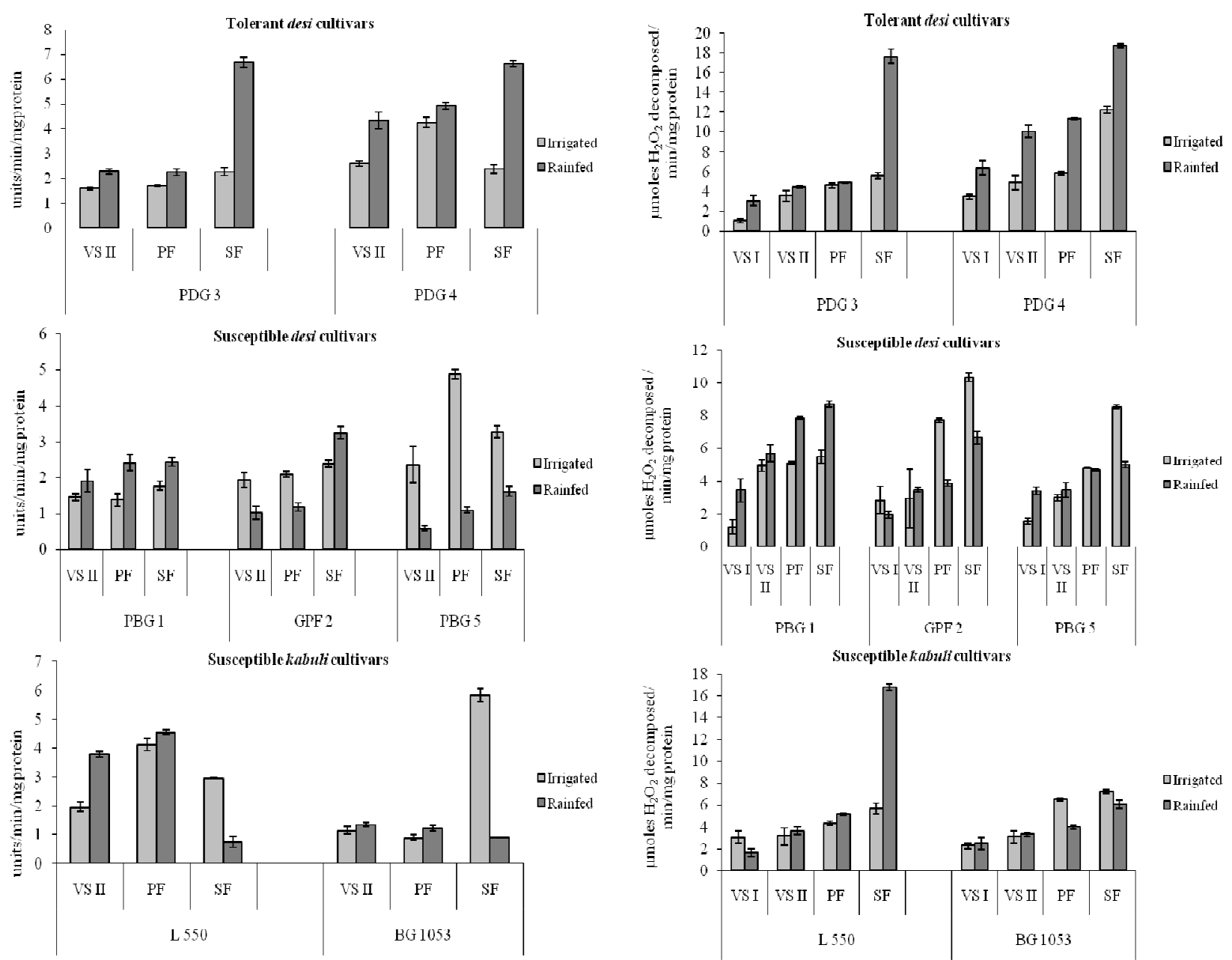

Fig. 1. Superoxide dismutase activity in leaves of desi and kabuli chickpea under irrigated and rainfed conditions. Vertical bars shows S.D. from mean of three replicates. ' $a$ ' represent significance at $1 \%$ as compared to control (Student t-test). VS II-vegetative stage II, PF-pre-flowering stage, SF-seed filling stage.

catalase activities under rainfed conditions, however, percentage increase in specific activity was relatively less as compared with tolerant cultivars (PDG 3 and PDG 4). Among kabuli susceptible cultivars, L 550 leaves showed greater CAT activities as a result of rainfed conditions. Due to drought stress, the percentage increase in average CAT activity in desi susceptible cultivars (PBG 1, GPF 2 and PBG 5) was higher compared to kabuli susceptible cultivars (L 550 and BG 1053), whereas, it was observed that the kabuli cultivars had more average CAT activity under irrigated conditions and comparable under rainfed condition than the desi cultivars.

Glutathione reductase (GR): Under rainfed conditions, activity and specific activity of GR increased in leaves with the plant development, peaked at vegetative stage II and thereafter declined towards plant maturity in all desi chickpea cultivars, however, in kabuli cultivars GR showed peak activity at pre-flowering stage (Fig. 3). Increase in average specific activity of GR under

Fig. 2. Catalase activity in leaves of desi and kabuli chickpea under irrigated and rainfed conditions. Vertical bars shows S.D. from mean of three replicates. ' $a$ ' represent significance at $1 \%$ as compared to control (Student $t$-test). VS I-vegetative stage I, VS II-vegetative stage II, PF-pre-flowering stage, $S F$ - seed filling stage.

stressed conditions over irrigated samples was observed in tolerant cultivars PDG 3 and PDG 4. This increase was $188 \%$ and $117 \%$, respectively, which was significantly more than the susceptible cultivars which in general, with exception to L 550, showed either decline or were comparable in specific activity over the control crop.

Peroxidase (POX): Under both irrigated and rainfed conditions, the chickpea cultivars (tolerant and susceptible) showed significant variation in peroxidase activity and significant variation was seen at all the growth stages and even within the cultivars. Maximum activity of POX was found at vegetative stage II in all the seven cultivars under both stress and normal control conditions and thereafter, the activity declined till maturity (Fig. 4). However, at vegetative stage II and seed filling stage upregulation in POX activity in tolerant cultivars was noticed to be more under rainfed conditions compared to irrigated conditions and the induction in activity was more in tolerant than in 

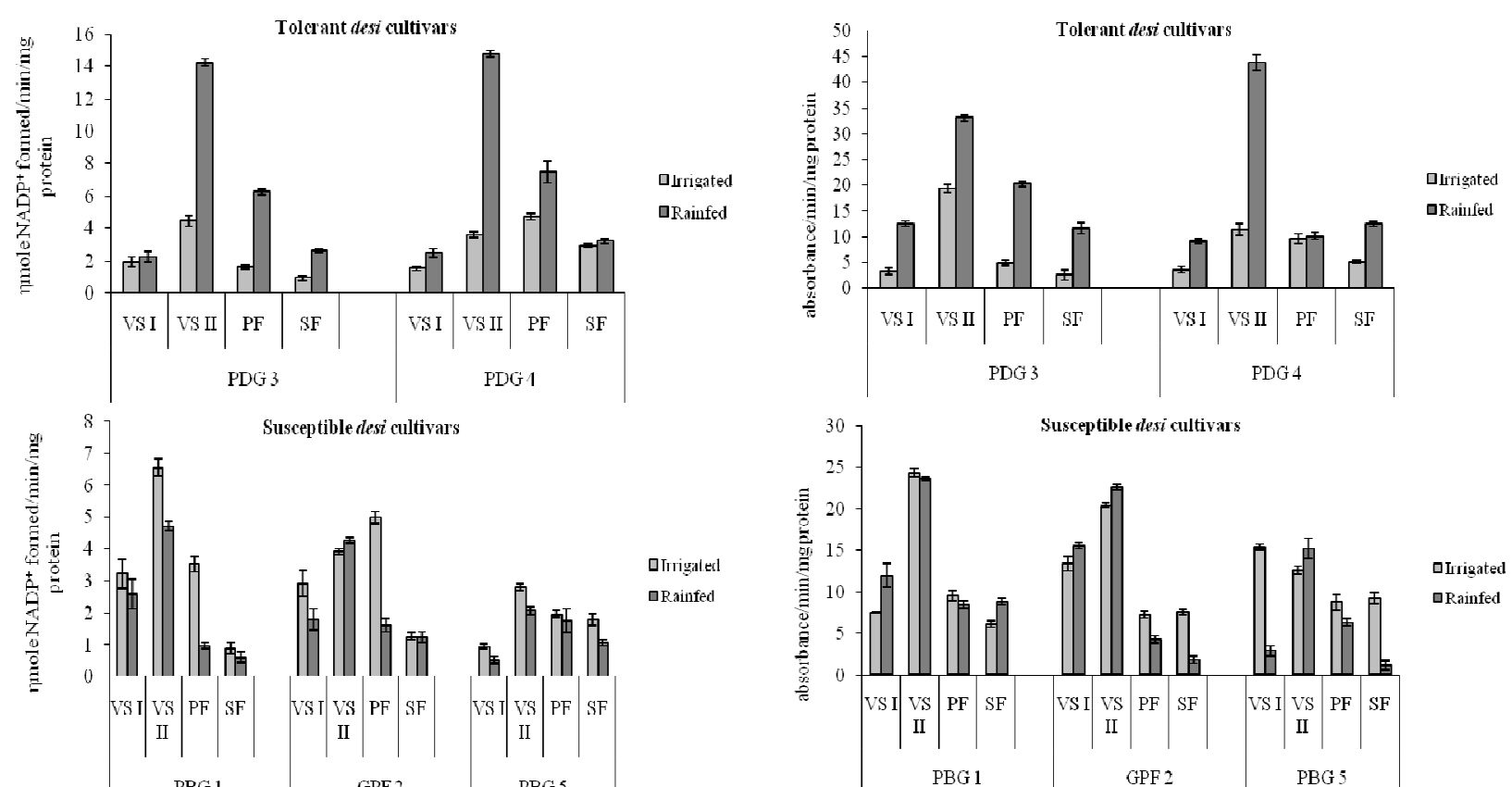

Suscep tible desi cultivars
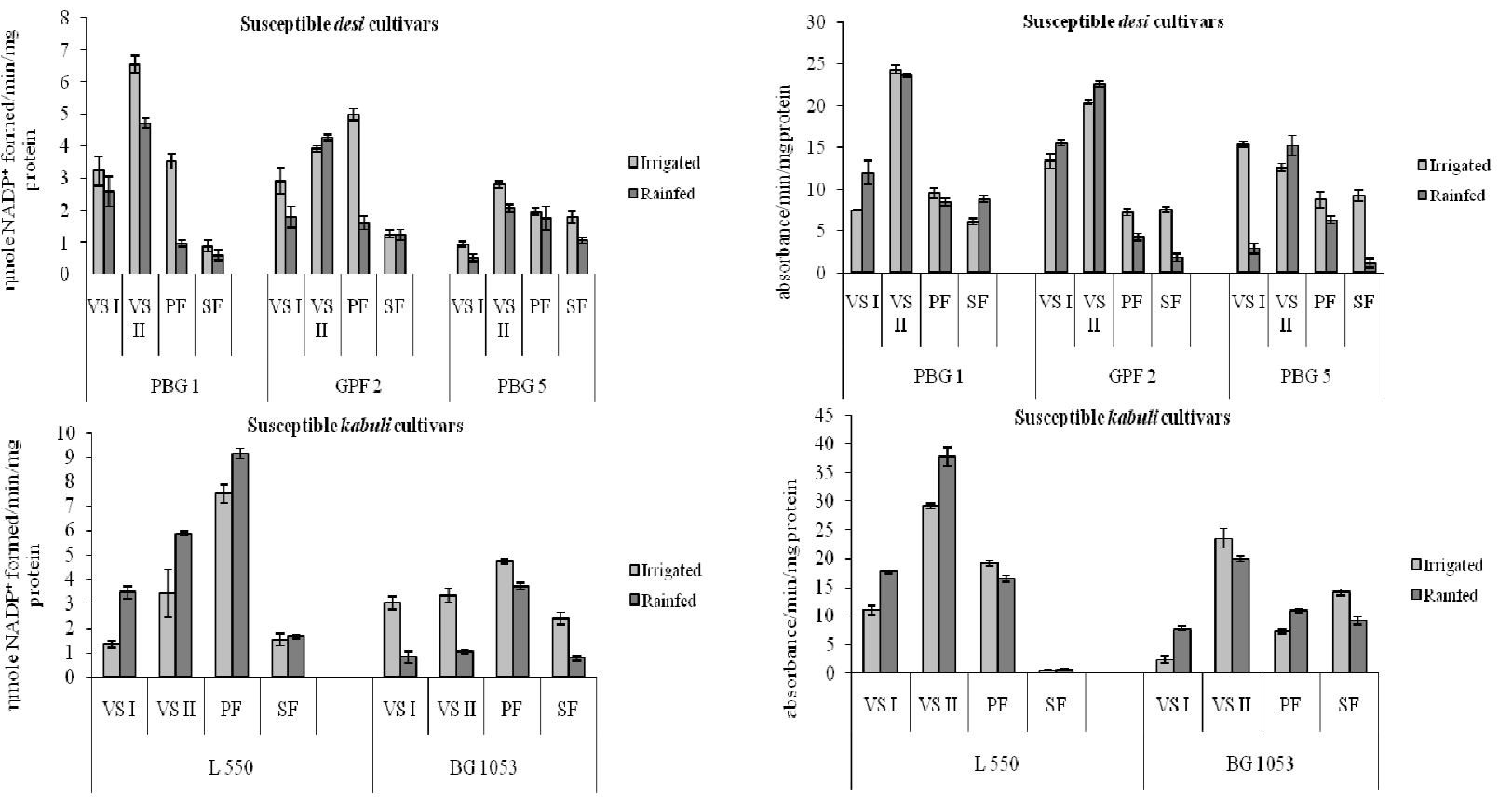

Fig. 3. Glutathione reductase activity in leaves of desi and kabuli chickpea under irrigated and rainfed conditions. Vertical bars shows S.D. from mean of three replicates. ' $a$ ' represent significance at $1 \%$ as compared to control (Student t-test). VS I-vegetative stage I, VS II-vegetative stage II, PF- preflowering stage, $S F$ - seed filling stage.

susceptible at these stages.

Average increase in specific activity of PDG 3 and PDG 4 was $189 \%$ and $161 \%$, respectively. On the contrary, in desi chickpea cultivars, decline or comparable in specific activity of POX under water deficit conditions was observed. However, under irrigated condition activities of susceptible cultivars (desi and kabuli) was found to be more compared to activities in leaves of tolerant cultivars. Rainfed condition resulted in significant reduction in activities in leaf tissue of PBG 5. Kabuli susceptible cultivar L 550 compared to desi susceptible cultivars and kabuli susceptible cultivar BG 1053 had higher POX activities under both normal and stressed conditions.

Ascorbate peroxidase (APX): At vegetative stage I, higher activities of ascorbate peroxidase were observed in all the cultivars under both irrigated and rainfed conditions (Fig. 5). APX activity declined thereafter, with growth and finally at seed filling stage APX activity was negligible. However, an increase in APX

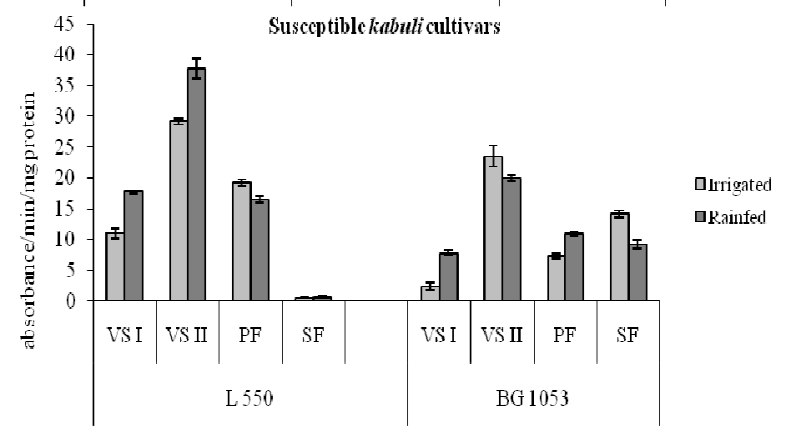

Fig. 4. Peroxidase activity in leaves of desi and kabuli chickpea under irrigated and rainfed conditions. Vertical bars shows S.D. from mean of three replicates. ' $a$ ' represent significance at $1 \%$ as compared to control (Student t-test). VS I-vegetative stage I, VS II-vegetative stage II, PF-pre-flowering stage, SF- seed filling stage.

activity in PDG 3 and PDG 4 leaves in response to drought stress at all stages of plant growth was observed. Increase in activity as well as specific activity of APX in PDG 3 and PDG 4 at vegetative stage I under rainfed conditions was much more as compared to susceptible cultivars. The drought tolerant genotypes have significant capacity to upregulate APX under drought stress as compared to almost negligible capacity of susceptible cultivars as reflected by mean activity data (Fig. 5).

Hydrogen peroxide $\left(\mathrm{H}_{2} \mathrm{O}_{2}\right)$ : In general, the content of hydrogen peroxide increased with progress of crop development (Fig. 6). Average $\mathrm{H}_{2} \mathrm{O}_{2}$ content in leaves of tolerant cultivars PDG 3 and PDG 4 and sensitive cultivars PBG 1 and L 550 was less in stressed leaves. However, major changes in $\mathrm{H}_{2} \mathrm{O}_{2}$ status occurred between pre-flowering and seed filling stages. At first instance, there appears to be no relationship of $\mathrm{H}_{2} \mathrm{O}_{2}$ content with drought tolerance. However on close scrutiny, it was observed that $\mathrm{H}_{2} \mathrm{O}_{2}$ level is less in 

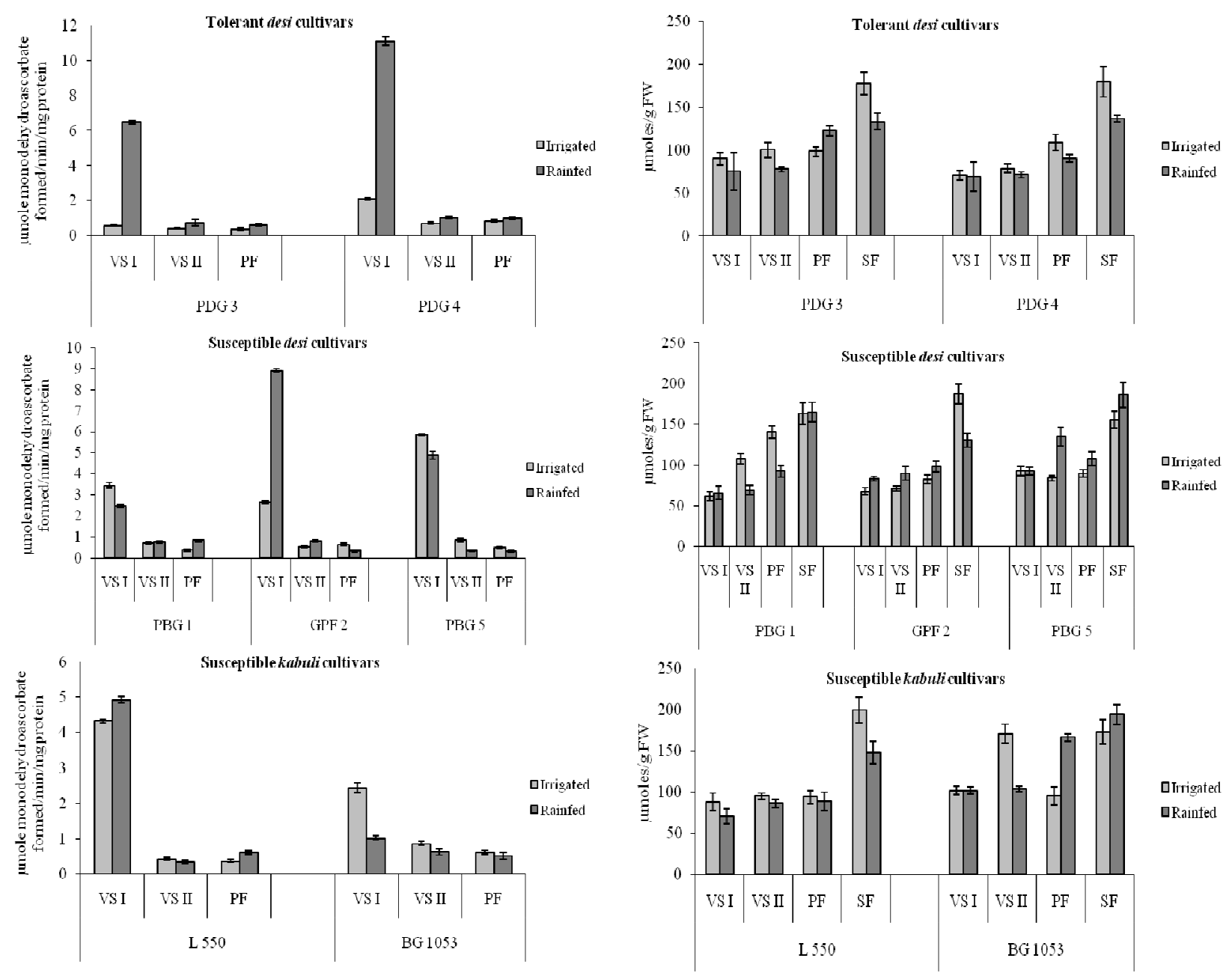

Fig. 5. Ascorbate peroxidase activity in leaves of desi and kabuli chickpea under irrigated and rainfed conditions. Vertical bars shows S.D. from mean of three replicates. ' $a$ ' represent significance at $1 \%$ as compared to control (Student t-test). VS I-vegetative stage I, VS II-vegetative stage II, PF-pre-flowering stage.

leaves of tolerant cultivars PDG 3 and PDG 4 both at pre-flowering and seed filling stages under rainfed conditions. Such behavior was not observed in sensitive desi chickpea cultivars.

Malondialdehyde (MDA): Rainfed induced drought stress may disturb normal ROS balance and promote lipid peroxidation of membranes, either by increased production or decreased scavenging of ROS in the cell. The detrimental effect of drought stress and genotypic variation in drought tolerance could be associated with levels of MDA. Drought stress resulted in increase in MDA content in cultivars (tolerant and susceptible) (Fig. 7). Differences in MDA content were significant at seed filling stage, for example, under irrigated conditions tolerant cultivars PDG 3 and PDG 4 have MDA content between 13-21 $\eta$ moles $\mathrm{g}^{-1} \mathrm{FW}$ which is lower than MDA content of 16-42 $\eta$ moles $\mathrm{g}^{-1} \mathrm{FW}$ of susceptible cultivars. Under drought stress, MDA content though increased in leaves but at seed filling stage the tolerant cultivars had lower MDA content

Fig. 6. Hydrogen peroxide content in leaves of desi and kabuli chickpea under irrigated and rainfed conditions. Vertical bars shows S.D. from mean of three replicates. ' $a$ ' represent significance at $1 \%$ as compared to control (Student t-test). VS I-vegetative stage I, VS II-vegetative stage II, PF-pre-flowering stage, SF- seed filling stage.

than that observed in susceptible cultivars (Fig. 7). Therefore, possibly it can be concluded on the basis of data obtained at seed filling stage the membrane instability, as reflected by lipid peroxidation, was higher in susceptible than in the tolerant chickpea cultivars under both stress and control condition.

Proline (PRO): Cultivar differences in proline content or interaction between cultivars and drought treatment or at different growth stages was observed (Fig. 8). Proline content increased gradually in all cultivars following stress and then decrease was observed at seed filling stage. An increase in proline content in response to drought in chickpea cultivars was seen in all cultivars at all stages compared to irrigated condition except PBG 5 (Fig. 8).

Total phenols: Total phenol accumulation was found to increase with age of plants (vegetative stage I to seed filling stage) in under drought and irrigated conditions (Fig. 9). The data obtained at pre-flowering and seed filling stages showed that tolerant cultivars 


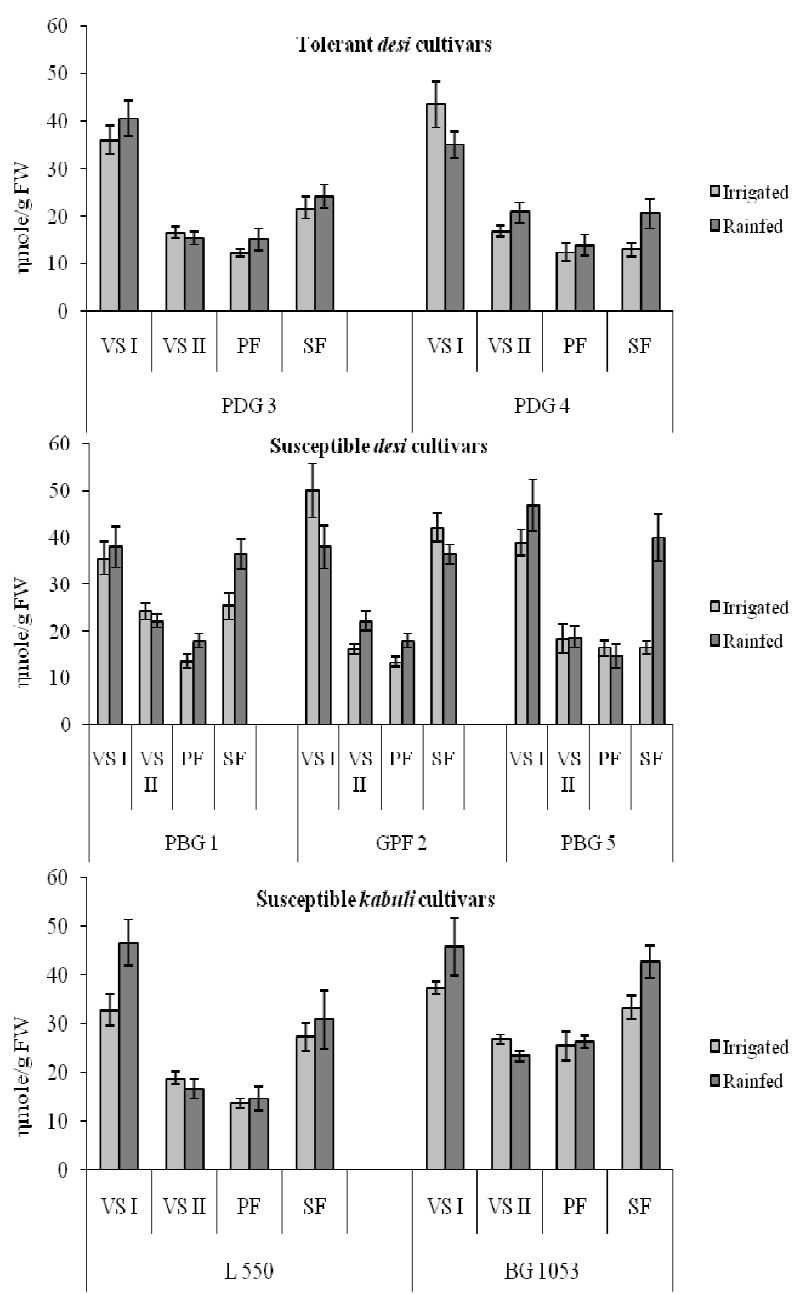

Fig. 7. Malondialdehyde content in leaves of desi and kabuli chickpea under irrigated and rainfed conditions. Vertical bars shows S.D. from mean of three replicates. 'a' represent significance at $1 \%$ as compared to control (Student t-test). VS I-vegetative stage I, VS II-vegetative stage II, PF-preflowering stage, $S F$ - seed filling stage.

PDG 3 and PDG 4 have higher phenolic content as compared to sensitive cultivars under drought conditions. In general, kabuli cultivars have higher phenolic content than susceptible chickpea cultivars under stressed conditions (Fig. 9).

\section{DISCUSSION}

Experimental findings on antioxidant system indicate that tolerant and sensitive cultivars responded differently under irrigated and rainfed conditions. Abiotic stresses are known to induce and enhance the expression of antioxidant genes encoding SOD, CAT, GR, POX and APX (Jiang and Zhang, 2002; Unyayar and Cekic, 2005; Gharari et al., 2014). Status of SOD activity modulates the relative amounts of superoxide radicals and hydrogen peroxide, the Haber-Weiss reaction substrates and decreases the risk of $\mathrm{OH}$ radical formation, which is highly reactive and may cause severe damage to membranes, protein and DNA (Bowler et al., 1992; Azooz et al., 2009). In this work,
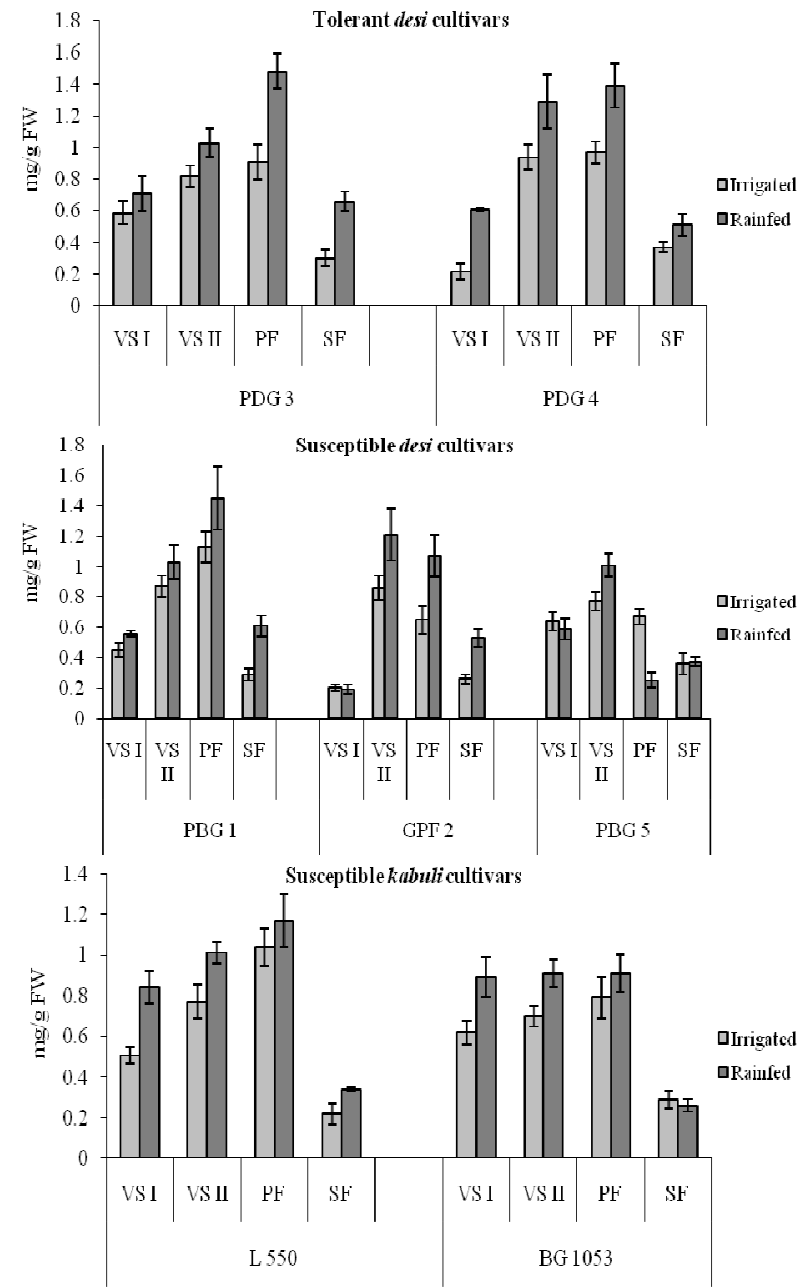

Fig. 8. Proline content in leaves of desi and kabuli chickpea under irrigated and rainfedconditions. Vertical bars shows S.D. from mean of three replicates. ' $a$ ' represent significance at $1 \%$ as compared to control (Student t-test). VS I-vegetative stage I, VS II-vegetative stage II, PF-pre-flowering stage, SF- seed filling stage.

drought stress increased SOD activity in leaves of tolerant PDG 3 and PDG 4 cultivars followed by susceptible PBG 1 and L 550 cultivars and reduced it in other sensitive ones suggesting that drought tolerant cultivars have a better superoxide radical scavenging ability (Fig. 1). Badawi et al. (2004) reported that transgenic tobacco plant over expressing $\mathrm{Cu} / \mathrm{Zn}$ SOD showed tolerance to salt and water stresses as well as polyethylene glycol induced stress. It has been shown that drought increased SOD activity in drought tolerant maize genotype and decreased in drought sensitive genotype (Moussa and Abdel-Aziz, 2008).

The lower SOD activity at vegetative stages (I and II) and pre-flowering stage under both irrigated and rainfed conditions indicated the lower synthesis of SOD at these stages compared to its activity at seed filling stage in leaves of chickpea plants (Fig. 1). The initial lower SOD activity could improve superoxide scavenging system of cells and favor accumulation of superoxide which mainly contributes in damaging the 


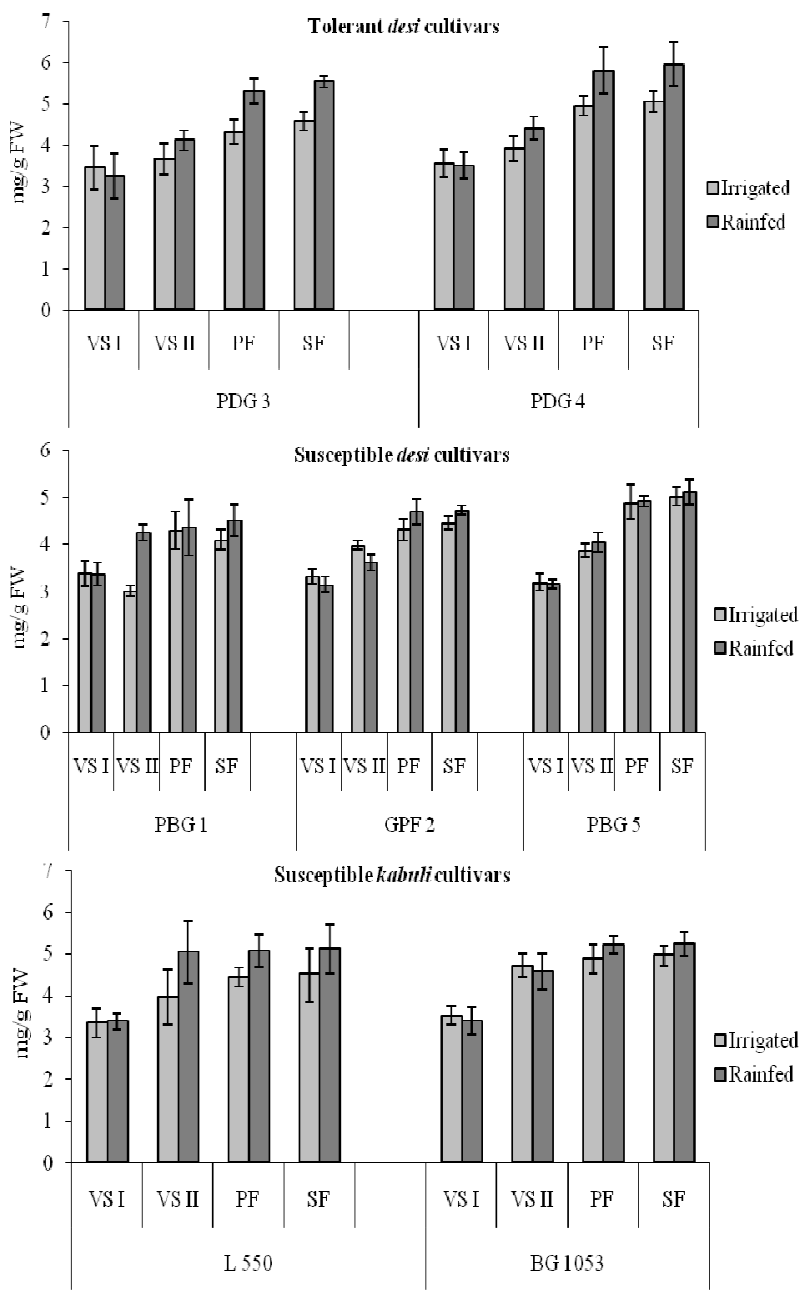

Fig. 9. Total phenols content in leaves of desi and kabuli chickpea under irrigated and rainfed conditions. Vertical bars shows S.D. from mean of three replicates. ' $a$ ' represent significance at $1 \%$ as compared to control (Student t-test). VS I-vegetative stage I, VS II-vegetative stage II, PF- preflowering stage, $S F$ - seed filling stage.

membrane (Pandey et al., 2010). However, leaves of tolerant cultivars were observed to have comparatively higher activity at vegetative and pre-flowering stages compared to sensitive cultivars and a significant higher induction at the of seed filling can be correlated with better seed development and thereby higher yield. These observations indicate that the leaf machinery in tolerant cultivars is not damaged to the extent as in susceptible cultivars due to oxidative stress and have impact on yield.

Catalase has a significant role in plant defence against drought induced oxidative stress. The main loci of CAT action are known to be the peroxisomes. The activity of this enzyme is sensitive to both drought and heat stresses (Jiang and Hoang, 2001). Decreasing activity of this enzyme in susceptible cultivars may relate to photo inactivation of the enzyme which is a sign for the advent of light stress in the plant that usually cause photo-inhibition of photosystem II, and this condition itself leads to hydrogen peroxide concentration and damage to cell membrane. Under salt stress, CAT was hypothesized to be the most important among $\mathrm{H}_{2} \mathrm{O}_{2}$ scavenging enzymes in chickpea (Eyidogan and Oz, 2007). Possibly, increase in catalase activity under rainfed conditions is related to increased level of drought tolerance in drought tolerant cultivars (Fig. 2). The increased activity of CAT at seed filling stage compared to other stages might be due to the enhanced superoxide dismutase activity and the increase in CAT activity might be useful in dismutating hydrogen peroxide that is the key product in reducing senescence under prolonged water stress conditions (Casano et al., 1999).

APX activity is rapidly induced by various stress conditions including drought (Mittler and Zilinskas, 1994), chilling (Prasad et al., 1994) and salt stress (Lopez et al., 1996) and has an important role in stress tolerance. Ascorbate peroxidase plays a vital role in scavenging hydrogen peroxide in water-water and ascorbate-glutathione cycles (Gill and Tuteja, 2010). APX scavenges hydrogen peroxide and uses ascorbate as an electron donor in plants. According to the results of present study, at vegetative stage I APX activity was noticed to be maximum and the activity was relatively lower during other stages under both conditions (Fig. 5). Water stress induced stimulation of APX activity was more pronounced in tolerant cultivars than in sensitive ones. Moreover, the activities of APX in both tolerant cultivars were increased under drought stress by $168 \%$ and $256 \%$ indicating their possible role in drought tolerance (Fig. 5). Sairam et al. (1998) have also observed higher APX activity in tolerant genotypes compared to susceptible ones under water stress. Higher APX activity in drought tolerant cultivars under water deficit conditions might help cultivars in maintaining the required levels of hydrogen peroxide.

Glutathione reductase, which catalyzes the reduction of oxidized glutathione (GSSG) to reduced glutathione (GSH) is an important endogenous antioxidant (Chalapathi Rao and Reddy, 2008). GR activity was higher in PDG 3 and PDG 4 under control and stress conditions and maximum activity was evident at vegetative stage II and pre-flowering stage (Fig. 3). As a result of rainfed condition, average GR specific activity in leaves of both kabuli susceptible cultivars was noticed to be more than desi susceptible cultivars. Increase in GR activity has been correlated with increased synthesis of GR protein under stress (Edwards et al., 1993). Edjolo et al. (2001) reported greater GR activity in leaves of tolerant poplar genotypes under drought stress than sensitive genotypes. Similar results came from Kellos et al. (2008) who reported significantly higher GR activity in leaf tissues of tolerant maize variety than the sensitive variety under ABA induced stress conditions. Due to higher APX activity at vegetative stage I of chickpea cultivars observed under both conditions resulted in accumulation of monodehydroascorbate 
and therefore, enhanced GR activity at later vegetative stage II and pre-flowering stage (Fig. 3) may help in maintaining a high ratio of GSH/GSSG which is required for the generation of ascorbate by utilizing monodehydroascorbate and also for activation of several chloroplastic $\mathrm{CO}_{2}$ fixing enzymes (Asada and Takahashi, 1987). Moreover, regenerated ascorbate might further play a role in non-enzymatic scavenging of superoxide and hydrogen peroxide radicals and protect chickpea leaves from ROS. Thus elevated GR levels may prevent the formation of free radicals in the leaves of tolerant chickpea cultivars under water deficit stress conditions.

Peroxidases are the major scavengers of hydrogen peroxide in chloroplasts and cytosol. They also have important roles in growth, development, lignifications and subarization processes (Asada and Takashashi, 1987). So, increasing activity of this enzyme in drought stress perhaps shows the accumulation of hydrogen peroxide in this condition (Csiszar et al., 2005). Therefore, higher POX activity under drought stress in tolerant cultivars and L 550 (susceptible kabuli cultivar) could be a sign of an efficient stress response mechanism (Fig. 4). Simova-Stoilova et al. (2009) also observed increase in peroxidase activity in flag leaves of four wheat varieties differing in drought tolerance under field conditions under severe drought conditions. They suggested that increase was in accordance with the membrane-stabilizing function of this enzyme. The present investigation also revealed that activity of POX was significantly increased at vegetative stages (I and II) but reduced at pre-flowering and seed filling stages under irrigated and rainfed conditions (Fig. 4). However, higher activity was also observed at seed filling stage in tolerant cultivars under the drought condition compared to control condition and thereby, would be helping in detoxification of hydrogen peroxide produced due to higher SOD activity at this critical stage of chickpea development.

Kalefetoglu - Macar and Ekmekci (2009) reported that proline content in the leaves under drought condition was higher in tolerant chickpea cultivar than in a sensitive cultivar. However, such a generalization could not be observed in present study though percentage increase in the mean proline content of tolerant cultivars with exception to GPF 2 was more than other cultivars (Fig. 8). Increase in leaf proline content with decrease in water supply means that an efficient mechanism for osmotic regulation, stabilizing sub-cellular structures and cellular adaptation to water stress is available (Khamssi et al., 2010). Proline may act both as a metabolic substrate to sustain the needs of rapidly dividing cells and, in turn, as a feedback signal molecule to fine-tune developmental processes such as flower transition. Raut et al. (2003) reported that in five drought tolerant chickpea cultivars which when subjected to artificial drought stress showed 30 times more mean content of proline in stressed plants as compared to control.

Phenolics are the main class of secondary metabolites with important roles in abiotic stress tolerance due to their antioxidant properties (Ruiz and Romero, 2001; Hura et al., 2009). Drought stress caused significant increase in total phenolics in all chickpea cultivars in present study. However, higher accumulation of these solutes in tolerant ones might be the possible reason for their enhanced capacity to resist drought stress (Fig. 9). The accumulation of total phenol in tolerant plants might act synergistically with enzymatic and non-enzymatic antioxidative defence system to confer higher degree of stress tolerance. Wahid and Ghazanfar (2006) observed that enhanced synthesis of soluble phenolics is directly correlated with salt and heat tolerance in sugarcane. Chakraborty and Pardhan (2012) reported increased proline and total phenol contents in leaves of four wheat varieties under drought stress conditions.

One of the reactions that speed up in the presence of ROS is peroxidation of membrane lipids which lead to production of aldehydes like malondialdehyde and other products like ethylene (Liu and Hoang, 2000; Jiang and Huang, 2001). The peroxidation of lipids in the cell membrane is one of the most damaging cellular responses observed in response to drought stress (Thankamani et al., 2003) and the amount of lipid peroxidation is considered to be one of the determinants which indicate the extremity of stress experienced by a plant. In the present investigation, it was observed that although MDA content increased in all chickpea cultivars during drought stress, MDA content in susceptible cultivars was more than that of tolerant cultivars (Fig. 7). Tatar and Gevrek (2008) reported that MDA content in wheat leaves increased with severity of drought stress.

Increased concentrations of hydrogen peroxide, a strong oxidant, and cause localized oxidative damage, disruption of metabolic functions and lipid peroxidation (Zlatev et al., 2006). However, besides being an ROS, hydrogen peroxide is also a signal molecule, which is involved in signal transduction mechanisms for several processes in plants such as stomatal closure, root growth and responses to pathogen challenge (Neill et al., 2002; Laloi et al., 2004; Desikan et al., 2005). Thus, levels of hydrogen peroxide are efficiently controlled to maintain balance between production and breakdown. In this study, although hydrogen peroxide accumulation increased during drought stress in tolerant and susceptible cultivars (Fig. 6), there was a lower hydrogen peroxide levels in tolerant cultivars, indicating greater antioxidant activity and also higher proline and total phenol contents. Kellos et al. (2008) reported accumulation of higher $\mathrm{H}_{2} \mathrm{O}_{2}$ content in leaf tissue of sensitive genotype of maize as compared to tolerant ones under drought stress induced by polyethylene 
glycol.

In general, with the age of plant, the activities of superoxide dismutase (SOD) and catalase (CAT) increased but the activities of glutathione reductase (GR), ascorbate peroxidase (APX) and peroxidase (POX) decreased. Both APX and POX are actively involved in detoxification of ROS by breaking down hydrogen peroxide; therefore, it seems that these enzymes have greater role in tolerance during initial drought stress conditions. Chakraborty et al. (2002) also reported that POX activities increased initially in leaves of all tea cultivars following drought stress. The relatively low activity of APX and POX during seed filling stage could be because old leaves generally contain low concentration of antioxidants and that is why old leaves are more prone to enhanced oxidative injury than the young leaves. Chickpea is especially vulnerable to soil drought at flowering and seed filling stages and the activities of GR and SOD and CAT at these respective stages significantly increased under drought stress compared with irrigated condition. SOD contributes to later accumulation of hydrogen peroxide and the hydrogen peroxide produced is metabolized by CAT and also by POX. It has also been reported that ABA treatment or drought increased the activity of SOD in mature leaves of Arabidopsis (Jung, 2004) and wheat (Keles and Oncel, 2002). Thus, combination of activities of the different enzymes is essential for tolerance. At vegetative stage II and pre-flowering stage, hydrogen peroxide and malondialdehyde were noticed to be lowered compared to other stages, thereby, suggesting GR would be playing major role in providing tolerance against drought conditions in chickpea cultivars.

\section{Conclusion}

It was concluded that the changes in the activities of antioxidant enzymes might be due to differential expression of corresponding genes at different stages of growth and might be responsible for providing tolerance to drought tolerant cultivars. Thus, status of antioxidant enzymes could be a very useful tool for depicting drought tolerance of chickpea, which could be useful to plant breeders for developing drought tolerant cultivars. However, further studies are needed to confirm the role of antioxidant enzymes for depicting drought tolerance in a large number of genotypes.

\section{ACKNOWLEDGEMENT}

The first author is thankful to Department of Science and Technology (DST), New Delhi for supporting this research work through providing INSPIRE Fellowship.

\section{REFERENCES}

Asada, K. and Takahashi, M. (1987). Production and scavenging of active oxygen in chloroplasts. In: Klye, D. J;
Osmond, C. B. and Arntzen, C. J. Eds. Photoinhibition. Elsevier, Amsterdam.

Ashraf, M. (2009). Biotechnological approach of improving plant salt tolerance using antioxidants as markers. Biotechnology Advances, 27: 84-93.

Azooz, M. M., Ismail A. M. and Abou-Elhamd, M. F. (2009). Growth, lipid peroxidation and antioxidant enzyme activities as a selection criterion for the salt tolerance of three maize cultivars grown under salinity stress. International Journal of Agriculture and Biology, 1:121126.

Badawi, G. H, Yamauchi, Y., Shimada, E., Sasaki, R., Kawano, N., Tanaka, K. and Tanaka, K. (2004). Enhanced tolerance to salt stress and water deficit by over expressing superoxide dismutase in tobacco (Nicotiana tabacum) chloroplasts. Plant Science, 166: 919-928.

Bartoli, C. G., Simontacchi, M., Tambussi, E., Beltrano, J., Montaldi, E. and Puntarulo, S. (1999). Drought and watering-dependent oxidative stress: effect on antioxidant content in Triticum aestivum L. leaves. Journal of Experimental Botany, 50: 375-383.

Bates, L. S., Waldren, R. P. and Teare, I. D. (1973). Rapid determination of free proline content for water stress studies. Plant Soil, 39: 205-207.

Battana, S. and Ghanta, R. G. (2014). Antioxidative enzyme responses under single and combined effect of water and heavy metal stress in two Pigeon pea cultivars. Journal of Scientic and Innovative Research, 3: 72-80.

Bowler, C., Van Montague, M. and Inze, D. (1992). Superoxide dismutase and stress tolerance. Annual Review of Plant Physiology and Plant Molecular Biology, 43: 83-116.

Casano, L. M., Martin, M., Zapauta, J. M. and Sabater, B. (1999). Leaf age and paraquate concentration dependent effects on the level of enzymes protecting against photo-oxidative stress. Plant Science, 149: 13-22.

Chakraborty, U. and Pardhan, B. (2012). Drought stress-induced oxidative stress and antioxidant responses in four wheat (Triticum aestivum L.) varieties. Archives of Agronomy and Soil Science, 58: 617-630.

Chakraborty, U., Dutta, S. and Chakraborty, B. N. (2002). Response of tea plants to drought stress. Biologia Plantarum, 45: 557-562.

Chalapathi Rao, A. S. V. and Reddy, A. R. (2008). Glutathione reductase: a putative redox regulatory system in plant cells. In: Khan, N.A; Singh, S. and Umar S. eds. Sulfur assimilation and abiotic stresses in plants, 111-147pp. Springer, The Netherlands.

Chance, B. and Machly, A. C. (1955). Assay of catalases and peroxidases. Methods in Enzymology, 2: 764-775.

Chaparzadeh, N., Amico, M.L.D., Khavari-Nejad, R.A., Izzo, R. and Navari-izzo, F. (2004). Antioxidative responses of Calendula officinalis under salinity conditions. Plant Physiology and Biochemistry, 42: 695701.

Chugh, V., Kaur, N. and Gupta, A. K. (2011). Evaluation of oxidative stress tolerance in maize (Zea mays L.) seedlings in response to drought. Indian Journal of Biochemistry and Biophysics, 48: 47-53.

Csiszar, J., Feher-Juhasz, E., Kotai, E., Ivankovits-Kiss, O., Horvath, G. V., Mai, A., Galle, A., Tari, I., Pauk, J., Dudits, D. and Erdei, L. (2005). Effect of osmotic stress on antioxidant enzyme activities in transgenic wheat calli bearing MSALR gene. Acta Biologica Szegediensis, 49: 49-50. 
Desikan, R., Hancock, J. T., Bright, J., Harrison, J., Weir, I., Hooley R. and Neill, S. J. A. (2005). Role for ETR 1 in hydrogen peroxide signaling in stomatal guard cells. Plant Physiology, 137: 831-834.

Devi, R., Kaur, N. and Gupta, A. K. (2012). Potential of antioxidant enzymes in depicting drought tolerance of wheat (Triticum aestivum L.). Indian Journal of Biochemistry and Biophysics 49: 257-265.

Edjolo, A., Laffray, D. and Guerrier, G. (2001). The ascorbate-glutathione cycle in the cytosolic and chloroplastic fractions of drought-tolerant and drought-sensitive poplars. Journal of Plant Physiology, 158: 1511-1517.

Edwards, E. A., Enard, C., Creissen, G. P. and Mullineaux, P. M. (1993). Synthesis and properties of glutathione reductase in stressed peas. Planta, 192: 137-143.

Esterbauer, H. and Grill, D. (1978). Seasonal variation of glutathione and glutathione reductase in needles of Picea abies. Plant Physiology, 61: 119-121.

Eyidogan, F. and Oz, M. T. (2007). Effect of salinity on antioxidant responses of chickpea seedlings. Acta Physiologiae Plantarum, 29: 485-493.

Gharari, Z., Nejad, R. K., Band, R. S., Najafi, F., Nabiuni, M. and Irian, S. (2014). The role of $M n-S O D$ and $F e$ $S O D$ genes in the response to low temperature in chs mutants of Arabidopsis. Turkish Journal of Botany, 38: 80-88.

Gill, S. S. and Tuteja, N. (2010) Reactive oxygen species and antioxidant machinery in abiotic stress tolerance in crop plants. Plant Physiology and Biochemistry, 48: 909-930.

Heath, R.L. and Packer, L. (1968). Photoperoxidation in isolated chloroplasts I. Kinetics and stoichiometry of fatty acid peroxidation. Archives of Biochemistry and Biophysics, 125: 189-198.

Hsu, S. Y. and Kao, C. H. (2003). Differential effect of sorbitol and polyethylene glycol on antioxidant enzymes in rice leaves. Journal of Plant Growth Regulation, 39: 83-89.

Hura, T., Hura, K. and Grzesiak, S. (2009). Physiological and biochemical parameters for identification of QTLs controlling the winter triticale drought tolerance at the seedling stage. Plant Physiology and Biochemistry, 47: 210-214.

Jiang, M. and Zhang, J. (2002). Water stress induced abscisic acid accumulation triggers the increased generation of reactive oxygen species and up regulates the activities of antioxidant enzymes in maize leaves. Journal of Experimental Botany, 53: 2401-2410.

Jiang, Y. and Huang, B. (2001). Drought and heat stress injury to two cool-season turfgrasses in relation to antioxidant metabolism and lipid peroxidation. Crop Science, 41: 436-442.

Jung, S. (2004). Variation in antioxidant metabolism of young and mature leaves of Arabidopsis thaliana subjected to drought. Plant Science, 166: 459-466.

Kalefetoglu-Macar, T. and Ekmekci, Y. (2009). Alterations in photochemical and physiological activities of chickpea (Cicer arietinum L.) cultivars under drought stress. Journal of Agronomy and Crop Science, 195: 335 $-346$.

Kaur, H., Gupta, A. K., Kaur, N. and Sandhu, J. S. (2009). Differential response of the antioxidant system in wild and cultivated genotypes of chickpea. Plant Growth Regulation, 57: 109-114.

Kaur, K., Kaur, N., Gupta, A.K. and Singh, I. (2012). Exploration of the antioxidative defense system to characterize chickpea genotypes showing differential response towards water deficit conditions. Plant Growth Regulation, doi: 10.1007/s10725-012-9777-0.

Keles, Y. and Oncel, I. (2002). Response of antioxidative defence system to temperature and water stress combinations in wheat seedlings. Plant Science, 163: 783-790.

Kellos, T., Timar, I., Szilagyi, V., Szalai, G., Galiba, G. and Koscy, G. (2008). Effect of abiotic stress on antioxidants in maize. Acta Biologica Szegediensis, 52: 173-174.

Khamssi, N. N., Golezani, K. G., Salmasi S. Z. and Najaphy, A. (2010). Effects of water deficit stress on field performance of chickpea cultivars. African Journal of Agricultural Research, 5: 1973-1977.

Kolarovic, L., Valentovic, P., Luxova, M. and Gasparikova, O. (2009). Changes in antioxidants and cell damage in heterotrophic maize seedlings differing in drought sensitivity after exposure to short-term osmotic stress. Plant Growth Regulation 59: 21-26.

Labudda, M. and Azam, F. M. S. (2014). Glutathione-dependent responses of plants to drought: a review. Acta societatis Botanicorum Poloniae, 83: 3-12.

Laloi, C., Apel, K. and Danon, A. (2004). Reactive oxygen signaling news. Current Opinion in Plant Biology, 7: 323-328.

Liu, X. and Huang, B. (2000). Heat stress injury in relation to membrane lipid peroxidation in creeping bent grass. Crop Science, 40: 503-510.

Lopez, F., Vansuyt, G., Casse-Delbart, F. and Fourcroy, P. (1996). Ascorbate peroxidase activity, not the mRNA level, is enhanced in salt-stressed Raphanus sativus plants. Plant Physiology, 97: 13-20.

Lowry, O. H., Rosebrough, N. T., Farr, A. L. and Randall, R. J. (1951). Protein measurement with folin phenol reagent. Journal of Biological Chemistry, 193: 265-275.

Marklund, S. and Marklund, G. (1974). Involvement of superoxide anion radical in the autoxidation of pyrogallol and a convenient assay for superoxide dismutase. European Journal of Biochemistry, 47: 169-174.

Miller, G., Suzuki, N., Ciftci-Yilmaz, S. and Mittler, R. (2010). Reactive oxygen species homeostasis and signaling during drought and salinity stresses. Plant Cell Environment, 33: 453-467.

Mirzaee, M., Moieni, A. and Ghanati, F. (2013). Effects of drought stress on the lipid peroxidation and antioxidant enzymes activities in two canola (Brassica napus L.) cultivars. Journal of Agricultural Science and Technology, 15: 593-602.

Mittler, R. and Zilinskas, B. A. (1994). Regulation of pea cytosolic ascorbate peroxidase and other antioxidant enzymes during progression of drought stress and following recovery from drought. Plant Journal, 5: $397-$ 405.

Moussa, H. R. and Abdel-Aziz, S. M. (2008). Comparative response of drought tolerant and drought sensitive maize genotypes to water stress. Australian Journal of Crop Science, 1: 31-36.

Nakano, Y. and Asada, K. (1987). Purification of ascorbate peroxidase in spinach chloroplasts: its inactivation in ascorbate depleted medium and reactivation by monodehydroascorbate radical. Plant Cell Physiology, 28: 131-140.

Neill, S. J., Desikan, R. and Hancock, J. T. (2002). Hydrogen peroxide. Current Opinion in Plant Biology, 5: 388-395.

Noreen, Z. and Ashraf, M. (2009). Change in antioxidant 
enzymes and some key metabolites in some genetically diverse cultivars of radish (Raphanus sativus L.). Environmental and Experimental Botany, 67: 395-402.

Pandey, H. C., Baig, M. J., Chandra, A. and Bhatt, R. K. (2010). Drought stress induced changes in lipid peroxidation and antioxidant system in genus Avena. Journal of Environmental Biology, 31: 435-440.

Patel, P. K. and Hemantaranjan, A. (2012). Antioxidant defence system in chickpea (Cicer arietinum L.): Influence by drought stress implemented at pre- and post - anthesis stage. American Journal of Plant Physiology, 7: 164-173.

Perez-Lopez, U., Robredo, A., Lacuesta, M., Sgherri, C., Munoz-Rueda, A., Navari-izzo, F. and Mena-Petite, A. (2009). The oxidative stress caused by salinity in two barley cultivars is mitigated by elevated $\mathrm{CO}_{2}$. Physiologia Plantarum, 135: 29-42.

Prasad, T. K., Anderson, M. D., Martin, B. A. and Stewart, C. R. (1994). Evidence for chilling-induced oxidative stress in maize seedlings and a regulatory role for hydrogen peroxide. Plant Cell, 6: 65-74.

Raut, J., Ghodeswar, R., Chavan, U. D. and Chavan, J. K. (2003). Biochemical constituents related to drought tolerance in chickpea. Indian Journal of Agricultural Biochemistry, 16: 103-104.

Ruiz, J. M. and Romero, J. (2001). Bioactivity of the phenolic compounds in higher plants. In: Atta-urRahman, ed. Studies in natural products chemistry. Bioactive Natural Products. 25: Part F, 651-683pp. Elsevier, Oxford.

Sairam, R. K., Desmukh, P. S. and Saxena, D. C. (1998). Role of antioxidant system in wheat genotypes tolerance to water stress. Biologia Plantarum, 41: 387-394.

Salekjalali, M., Haddad, R. and Jafari, B. (2012). Effects of soil water shortages on the activity of antioxidant enzymes and the contents of chlorophylls and proteins in barley. American-Eurasian Journal of Agricultural and Environmental Sciences, 12: 57-63.

Shannon, L. M., Kay, E. and Law, J. Y. (1966). Peroxidase isozymes from horseradish roots. I. Isolation and physical properties. Journal of Biological Chemistry, 241: 2166-2172.

Singh, S., Gupta, A.K. and Kaur, N. (2012). Differential responses of antioxidative defence system to long-term field drought in wheat (Triticum aestivum L.) genotypes differing in drought tolerance. Journal of Agronomy and Crop Science, 198: 185-195.

Simova-Stoilova, L., Demirevska, K., Petrova, T., Tsenov,
N. and Feller, U. (2009). Antioxidative protection and proteolytic activity in tolerant and sensitive wheat (Triticum aestivum L.) varieties subjected to long-term field drought. Plant Growth Regulation, 58: 107-117.

Swain, T. and Hills, E. (1959). The phenolic constituents of Prunus domestica. The quantitative analysis of phenolic constituents. Journal of the Science of Food and Agriculture, 10: 63-68.

Tatar, O. and Gevrek, M. N. (2008). Influence of water stress on proline accumulation, lipid peroxidation and water content of wheat. Asian Journal of Plant Sciences, 7: 409-412.

Thankamani, C. K., Chempakam, B. and Ashokan, P. K. (2003). Water stress induced changes in enzymatic activities and lipid peroxidation in black pepper (Piper nigrum). J. Med. Arom. Plant Science, 25: 646.

Turkan, I., Bor, M., Ozdemir, F. and Koca, H. (2005). Differential responses of lipid peroxidation and antioxidants in the leaves of drought tolerant $P$. acutifolius Gray and drought sensitive $P$. vulgaris $\mathrm{L}$. subjected to polyethylene glycol mediated water stress. Plant Science, 168: 223-231.

Turner, N. C., Wright, G. C. and Siddique, K. H. M. (2001). Adaptation of seed legumes (pulses) to water-limited environments. Advances in Agronomy, 71: 193-231.

Unyayar, S. and Cekic, F. O. (2005). Changes in antioxidative enzymes of young and mature leaves of tomato seedlings under drought stress. Turkish Journal of Biology, 29: 211-216.

Varshney, R. K., Song, C. and Saxena, R. K. (2013). Draft genome sequence of chickpea (Cicer arietinum) provides a resource for trait improvement. Nature Biotechnology, 31: 240-46.

Verma, K. K., Singh, M., Gupta, R. K. and Verma, C. L. (2014). Photosynthetic gas exchange, chlorophyll fluorescence, antioxidant enzymes and growth responses of Jatropha curcas during soil flooding. Turkish Journal of Botany, 38: 130-40.

Wahid, A. and Ghazanfar, A. (2006). Possible involvement of some secondary metabolites in salt tolerance of sugarcane. Journal of Plant Physiology, 163: 723-730.

Zhang, J. X. and Kirkham, M. B. (1996). Antioxidant response to drought in sunflower and sorghum seedlings. New Phytologist, 132: 361-373.

Zlatev, Z. S., Lidan, F. C., Ramalho, J. C. and Yordanova, I. T. (2006). Comparison of resistance to drought of three bean cultivars. Biologia Plantarum, 50: 389-394. 